\title{
Fluxless Process of Fabricating In-Au Joints on Copper Substrates
}

\author{
William W. So and Chin C. Lee, Senior Member, IEEE
}

\begin{abstract}
Based on the oxidation-free fluxless bonding technology, we have developed a bonding process to manufacture In-Au joints on copper substrates. $4 \mathrm{~mm} \times 4 \mathrm{~mm}$ Si blank dice and $6 \mathrm{~mm} \times 6 \mathrm{~mm}$ copper substrates are used. The dice are deposited with indium-rich $\mathrm{Au} / \mathrm{In} / \mathrm{Cr}$ multilayer structure in a single high vacuum cycle to prevent oxidation. Right after deposition, the outer Au layer interacts with the In layer to form AuIn 2 intermetallic compound. This compound is quite stable and thus can protect the In layer against oxygen penetration when it is exposed to ambient. On the other hand, it can easily be dissolved by the molten In during the bonding process. The substrate is deposited with $\mathrm{Cr}$ and $\mathrm{Au}$. The dice are bonded to the substrates at $180^{\circ} \mathrm{C}$ in inert environment. Nearly void-free joints have been obtained as examined by a 75 MHz Scanning Acoustic Microscope (SAM). Cross sections of several samples are studied using SEM and EDX to identify the microstructure and composition of the joints. Shear test has been performed according to MIL-STD-883C. All the well-bonded devices meet the shear test force requirement. Despite the large mismatch on the thermal expansion coefficient between silicon and copper, no die cracking is observed on the 30 samples produced. To assess further endurance, two samples underwent thermal cycling test between -50 and $120{ }^{\circ} \mathrm{C}$ for 20 cycles. SAM examination indicates that the joints incur little degradation after the test. This bonding method requires neither flux nor scrubbing action. It is thus particularly attractive for bonding devices that cannot be exposed to flux.
\end{abstract}

Index Terms-Copper, fluxless bonding technique, indium-gold alloy, soldering, solders.

\section{INTRODUCTION}

D UE TO its high electrical and thermal conductivities, copper has been widely used as a substrate to mount semiconductor device chips. To achieve high thermal conductance, solders are commonly used as the bonding medium. The use of solder to achieve a joint is known as the soldering process. It is understood that soldering, by definition, needs relatively low process temperature. Low temperature is possible because the solder alloy contains at least one element that has a low melting temperature. Solders are usually categorized into two types, hard solder and soft solder, depending on the yield strength. The hard solder has very high yield strength, and thus incurs only elastic deformation under stresses in normal

Manuscript received June 4, 1999; revised January 10, 2000. This paper was recommended for publication by Editor S. Canumalla upon evaluation of the reviewers' comments. This work was presented at the 49th Electronic Components and Technologies Conference, San Diego, CA, June 1-4, 1999.

W. W. So is with Alpha Photonics, Monterey Park, CA 91754 USA.

C. C. Lee is with the Department of Electrical and Computer Engineering, University of California, Irvine, CA 92697-2625 USA (e-mail: cclee@ece.uci.edu).

Publisher Item Identifier S 1521-3331(00)03912-X. usage. Accordingly, it does not have thermal fatigue and creep movement phenomena. However, the hard solder does not help relieve the stresses developed in a structure because of lack of plastic strain or deformation. The soft solder, on the other hand, has very low yield strength, and thus incurs plastic deformation under stresses in normal usage. It is quite ductile and can endure large plastic strain or deformation before breakage. It, therefore, can help relieve the stresses developed in a structure through plastic deformation. However, the plastic strain brings with it the problems of thermal fatigue and creep movement. It is thus clear that the choice of solders depends on specific applications and design.

At present, the most widely used solder is still the lead-tin $(\mathrm{Pb}-\mathrm{Sn})$ alloy. Due to potential environmental hazard of lead, lead-containing solder has been banned in applications involving water and food. It may eventually be banned in electronic products [1]. Thus, there have been many efforts in developing alternative solders that do not contain lead. In electronic packaging and assembly, solders come in various forms of ingot, wire, paste, preforms, or spheres. During the assembly process, the oxidation of the solder produce a solid oxide film adhering to the molten solder. The solid oxide film has very high melting temperature and becomes a barrier preventing the molten solder from having contact with the parts to be joined. As a result, chemical bonds cannot be formed between the solder and the parts. Therefore, to achieve bonding, the oxide must be broken up or removed one way or another. Besides, the base metal such as copper also gets oxidized easily and the oxide needs to be removed. The most common technique is to apply acid rosin flux. Another method is to use scrubbing action. In applications where flux cannot be used, fluxless processes are required. In fact, the fluxless process has long been a dream of many researchers.

Previously, we have developed an oxidation-free fluxless bonding technology [2]-[7]. In this technology, oxides and oxidation are prevented right in the beginning by depositing the solder material in one high vacuum cycle and by further protecting the material against oxidation with a stable intermetallic layer that is formed in situ in high vacuum. In this research, this technology is applied to bonding silicon dice to copper substrates using the In-Au binary material system. Indium-rich In-Au alloy is chosen as the resulting joint due to indium ductility.

To assess the soldering difficulty caused by oxides and oxidation, the fundamental principle of soldering action is first presented. The purpose of fluxes in soldering operations is briefly mentioned [8]. To help understand the fluxless bonding technology, the In-Au phase diagram is reviewed. We then report 


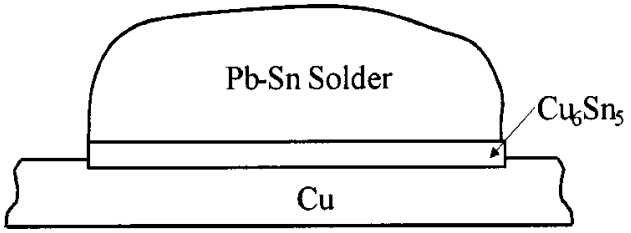

Fig. 1. Solder joint formation.

the principle of the fluxless technology as applied to the In-Au system and the fabrication process realized. Experimental results and discussions are given. The paper is concluded with a short summary.

\section{Fundamental Principle OF Soldering ACtion}

The purpose of soldering process is to form joints or connections, i.e., to bond solder to a base material, usually metal. To achieve bonding, there must be mass transfer or charge transfer, or both. Diffusion bonding in conventional welding processes at high temperature is an example of using mass transfer principle. Soldering, on the other hand, is carried out at relatively low temperatures and diffusion is not adequate to ignite the bonding. Therefore, the initial bonding in soldering process is not caused by diffusion. Rather it is initiated by the formation of intermatallic compound, and thus can be seen as using charge transfer principle. The initial bonding is then followed by diffusion and further intermetallic formation. Let us take $\mathrm{Pb}-\mathrm{Sn}$ solder on copper as an example. During the soldering process, the $\mathrm{Pb}-\mathrm{Sn}$ alloy melts and gets into contact with copper. The $\mathrm{Sn}$ in the molten solder reacts with copper to form $\mathrm{Cu}_{6} \mathrm{Sn}_{5}$ intermetallic compound on the interface as portrayed in Fig. 1. It is this interfacial $\mathrm{Cu}_{6} \mathrm{Sn}_{5}$ layer that links the solder and copper together. Near this layer in the solder, $\mathrm{Sn}$ in the $\mathrm{Pb}-\mathrm{Sn}$ alloy is somewhat depleted. This intermetallic formation occurs on almost all soldering systems.

\section{PRINCIPLE OF FluX ACTION}

Since the fundamental principle of soldering is the intermetallic formation, the soldering environment must provide the proper condition for the chemical reaction to occur. However, both the solder and the base metal have oxides on their surfaces. These oxide layers have very high melting temperatures and do not melt at the soldering temperature. For example, the melting temperatures of $\mathrm{SnO}$ and $\mathrm{SnO}_{2}$ are 1080 and $1630{ }^{\circ} \mathrm{C}$, respectively. They are also lighter than the solder. They thus form barriers on solder surfaces and prevent the molten solder from having intimate contact with the base metal. As a result, bonding cannot be achieved without first dealing with the oxide. This is where fluxes come into the picture. The purpose of flux is to reduce the oxide and to protect both solder and base metal against further oxidation.

There are many flux formulations [8]. The key ingredient of fluxes is rosin that is obtained by distilling turpentine from the sap of various pine trees. Turpentine is an oleoresin that is a soft resin among natural resins. The principle source of natural resins is the protective coating that hardens from the sticky substance exuded from many trees when their bark is injured. Synthetic resins have properties similar to natural resins but differ

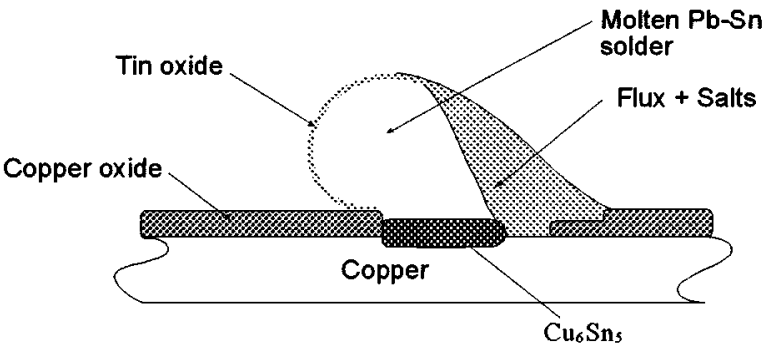

Not to scale

Fig. 2. Molten flux converts oxides into salts to expose fresh solder and base metal, and shield them from further oxidation.

from them chemically. Rosin is composed of various monocarboxylic acids of alkylated hydrophenanthrene nuclei, also known as resin acids. Major resin acids include abietic, neoabietic, dehydroabietic, palustric, pimaric, and isopimaric acids. Resin acids can react with metal oxides such as $\mathrm{CuO}$ and $\mathrm{SnO}$ as follows:

$$
\begin{aligned}
& 2 \mathrm{R}-\mathrm{COOH}+\mathrm{CuO} \rightarrow(\mathrm{R}-\mathrm{COO})_{2} \mathrm{Cu}+\mathrm{H}_{2} \mathrm{O} \\
& 2 \mathrm{R}-\mathrm{COOH}+\mathrm{SnO} \rightarrow(\mathrm{R}-\mathrm{COO})_{2} \mathrm{Sn}+\mathrm{H}_{2} \mathrm{O}
\end{aligned}
$$

where $\mathrm{R}$ represents the carboxyl residue. For the case of abietic acid, $\mathrm{R}=\mathrm{C}_{19} \mathrm{H}_{29}$. In above equations, the copper salt is green and the tin salt is tan. Both appear as a soapy film and are usually embedded in and mixed with the bulk of rosin.

As we can see, the oxide is now removed to expose the fresh molten solder and fresh base metal, as exhibited in Fig. 2. The molten solder flows on the base metal and readily react with it to form intermatallics. When this occurs, a bond is essentially produced upon cooling to room temperature. Since the molten solder is covered with the flux that is now in liquid form, further solder oxidation is prevented.

The flux process has worked very well over many decades. However, its major downside has recently appeared and become very serious due to the discovery and confirmation of severe ozone depletion by chlorofluorocarbons (CFC's) [9]. CFC's have traditionally been used to clean and remove flux residues on the printed circuit boards. Since the discovery of ozone depletion, many significant efforts have been spent on developing fluxes of which the residue does not need cleaning at all or can be cleaned using nonozone depletion agents such as water.

\section{Phase Diagrams AND Intermetallics}

To explain the fluxless bonding principle, it is appropriate to briefly review the binary phase diagrams and intermetallic compounds of the indium-gold system. Fig. 3 shows the In-Au phase diagram [10]. There are a total of fourteen equilibrium phases. Two of them are identified as intermetallic compounds AuIn (36.79 wt. \% of In) and AuIn 2 (53.8 wt.\% of In). The terminal solid solution $(\mathrm{Au})$ can take up to $7.8 \mathrm{wt} . \%$ In at $700{ }^{\circ} \mathrm{C}$. In contrast, there is no detectable solubility of gold in indium (In). There are four eutectic reactions that occur at $456.5,454.3$, 495.4 , and $156{ }^{\circ} \mathrm{C}$ with In wt. percentage of $24,28,42$, and $100 \%$, respectively. At room temperature, alloy with In composition above 54 wt.\% is a mixture of $\mathrm{AuIn}_{2}$ intermetallic com- 


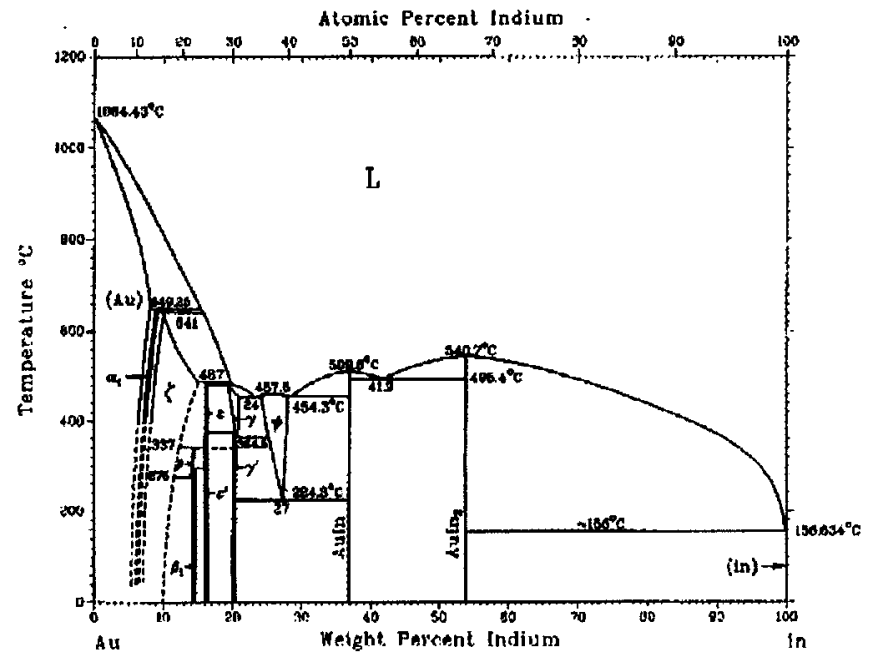

Fig. 3. Indium-gold binary phase diagram [10].

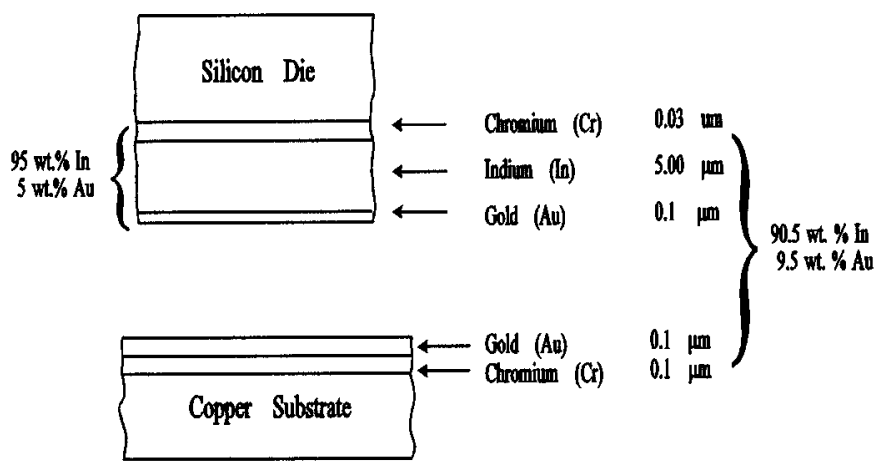

(Fiqure not to scale)

Fig. 4. Indium-gold multilayer composite design for fluxless bonding.

pound and (In) phase with a solidus temperature of $156^{\circ} \mathrm{C}$. Upon increasing the temperature above $156^{\circ} \mathrm{C}$, the alloy converts to a mixture of liquid phase $\mathrm{L}$ with $\mathrm{AuIn}_{2}$ grains. In the composition range between $36.8-54 \mathrm{wt}$.\% In, the alloy is a mixture of AuIn and $\mathrm{AuIn}_{2}$ intermetallic compounds with a solidus temperature of $495.4^{\circ} \mathrm{C}$. The $\psi$ phase has an indium composition of 24-28 wt.\%, around the stoichiometric value for $\mathrm{Au}_{3} \mathrm{In}_{2}$ phase. At $224.3{ }^{\circ} \mathrm{C}$, the $\psi$ phase decomposes by a eutectoid reaction into $\gamma^{\prime}$ phase, $\mathrm{Au}_{7} \operatorname{In}_{3}(20.0$ wt.\% of In), and AuIn intermetallic phase. A stable $\gamma$ phase with indium composition between 19.2-21 wt.\% In with an approximate stoichiometric value of $\mathrm{Au}_{9} \mathrm{In}_{4}$. In the composition range between 6-16 wt.\% In, the phases are not well characterized. However, a $\zeta$ phase with solubility ranging from $8-16 \mathrm{wt} . \%$ indium, and a narrow range of $\alpha_{1}$ phase were found below $641^{\circ} \mathrm{C}$. Below $487{ }^{\circ} \mathrm{C}$, there are $\varepsilon$ and $\varepsilon^{\prime}$ order and disorder phases around the stoichiometric value for $\mathrm{Au}_{3} \mathrm{In}(16.25 \mathrm{wt} . \% \mathrm{In})$. Finally, there is a narrow range which includes two phases, $\beta$ and $\beta_{1}$, that are found below $337^{\circ} \mathrm{C}$.

\section{DESIGN PRINCIPLE AND FABRICATION OF JOINTS}

Fig. 4 exhibits the In-Au multilayer composite for fluxless bonding. Chromium, indium, and gold are deposited on a silicon wafer (dice) in a single high vacuum cycle ( $10^{-6}$ torr) to inhibit indium oxidation. The chromium provides adhesion to (a)

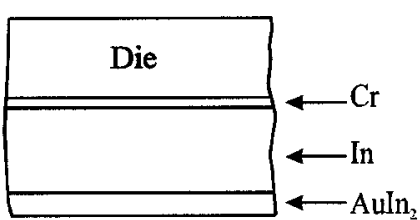

As Deposited

(b)

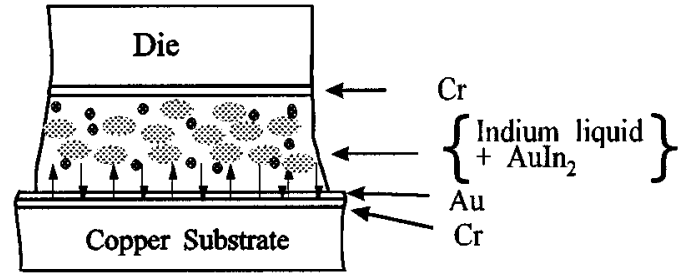

$157^{\circ} \mathrm{C}$

(c)

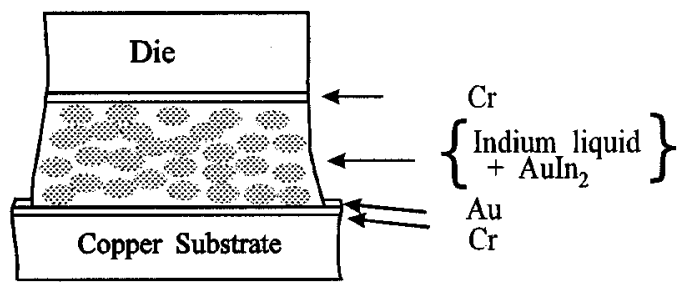

$157-180^{\circ} \mathrm{C}$

(d)

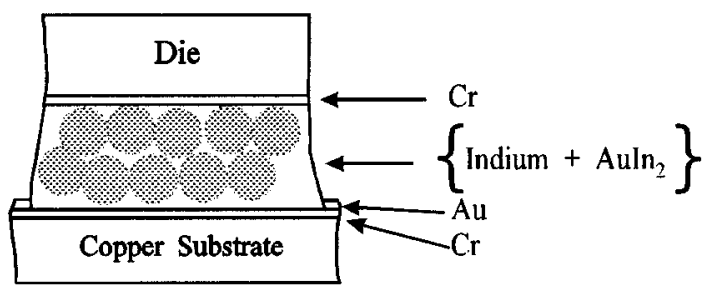

Room Temperature

Fig. 5. The bonding principle of In-Au system: (a) multilayer In-Au composite on the die converts to In-AuIn 2 composite right after deposition, (b) at $157^{\circ} \mathrm{C}$, indium layer melts and turns the composite into a mixture of liquid phase with $\mathrm{AuIn}_{2}$ grains, (c) in $157-180^{\circ} \mathrm{C}$ range, more $\mathrm{AuIn}_{2}$ is produced, and (d) solidification of the mixture to form a joint below $157^{\circ} \mathrm{C}$.

the wafer. It was found that indium diffuses into gold through the grain boundaries of the AuIn 2 layer with a diffusion coefficient $D_{\circ}$ of $6.05 \times 10^{-4} \mathrm{~m}^{2} \mathrm{~s}^{-1}$ and activation energy of $0.97 \mathrm{ev}$ [11]. Therefore, right after deposition, the outer gold layer interacts with indium to form a AuIn $n_{2}$ compound layer due to the high interdiffusion coefficient. The $\mathrm{AuIn}_{2}$ compound remains stable even after nine months at room temperature [12], [13]. We thus expect it to prevent the inner indium layer from oxidation when the samples are removed from the vacuum chamber and exposed to atmosphere. Thus, right after deposition, the In-Au composite would convert into In-AuIn 2 composite. The substrate is made of copper and has dimensions of $6 \mathrm{~mm} \times 6 \mathrm{~mm}$ $\times 0.5 \mathrm{~mm}$ thick. On copper substrates, thin chromium and gold layers are deposited also in high vacuum.

The thickness of indium and gold on the die and gold on the substrate depend on the final composition of the joints required. For this design of indium-rich In-Au joints, the In and Au layers on the die are 5 and $0.1 \mu \mathrm{m}$, respectively. The Au layer on the substrate is $0.1 \mu \mathrm{m}$. If all the joining materials form a uniform 


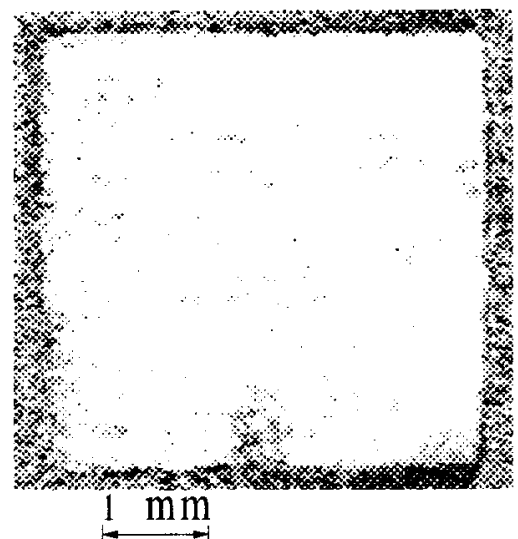

Fig. 6. Scanning acoustic microscopy image of a joint specimen produced with In-Au system depicted in Fig. 4.

joint, an overall composition of $10 \mathrm{wt} . \% \mathrm{Au}$ and $90 \mathrm{wt} . \%$ of In is expected. After the deposition, the silicon wafer was cleaved into $4 \times 4 \mathrm{~mm}$ dice.

Fig. 5 presents the principle of the bonding process for the In-Au system. In the bonding process, the silicon die and copper substrate are held together in a graphite boat using compression springs to apply a static pressure of $40-50 \mathrm{psi}$. The assembly is loaded into a furnace and heated to $180^{\circ} \mathrm{C}$ in a hydrogen environment for 5 minutes. Hydrogen is used just to prevent oxygen from getting into the sample, thus inhibiting indium oxidation during the bonding process. Upon heating, the indium layer in the In-AuIn 2 composite melts at $157^{\circ} \mathrm{C}$. The molten indium dissolves and breaks up the $\mathrm{AuIn}_{2}$ intermetallic layer to form a mixture of indium-rich liquid with $\mathrm{AuIn}_{2}$ grains. The liquid now has intimate contact with the gold layer on the copper substrate, and thus reacts with the gold to form $\mathrm{AuIn}_{2}$. When this reaction occurs, a joint is essentially produced. The AuIn $\mathrm{A}_{2}$ thus formed is dissolved in the liquid and becomes grains in the liquid. Accordingly, the composition of $\mathrm{AuIn}_{2}$ in the mixture increases. Upon cooling to room temperature, a solid joint is produced. Since the amount of gold is very small, the joint is an indium-rich In-Au alloy.

In the present bonding process, the dwell time at $180{ }^{\circ} \mathrm{C}$ is $5 \mathrm{~min}$. The sample is removed from the furnace and cooled to room temperature in about $20 \mathrm{~min} .30$ samples were produced for evaluation and examination. In this process, indium oxidation is inhibited. As a result, the use of flux to remove the oxide is not needed. This is contrary to many In- or Sn-based bonding processes that require flux to remove oxides in order to achieve bonding.

\section{EXPERIMENTAL RESULTS AND DISCUSSIONS}

To evaluate the quality of joints manufactured, a scanning acoustic microscope (SAM) is employed [14], [15]. Due to the relatively high acoustic attenuation of copper substrate, the operating frequency was reduced from 140 to $75 \mathrm{MHz}$ to keep the overall system loss within acceptable range. At $75 \mathrm{MHz}$, the spatial resolution is estimated to be $40 \mu \mathrm{m}$. The SAM is particularly useful in detecting voids inside optically opaque samples on a nondestructive basis. Voids show up with very high contrast in acoustic images because of mismatch in acoustic impedance

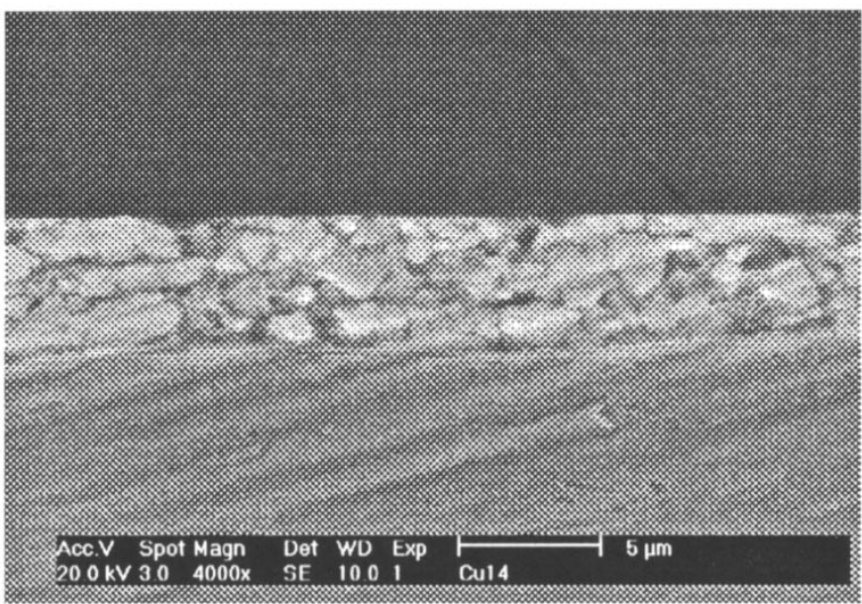

Fig. 7. SEM image of a joint fabricated with indium-gold system.

(a)
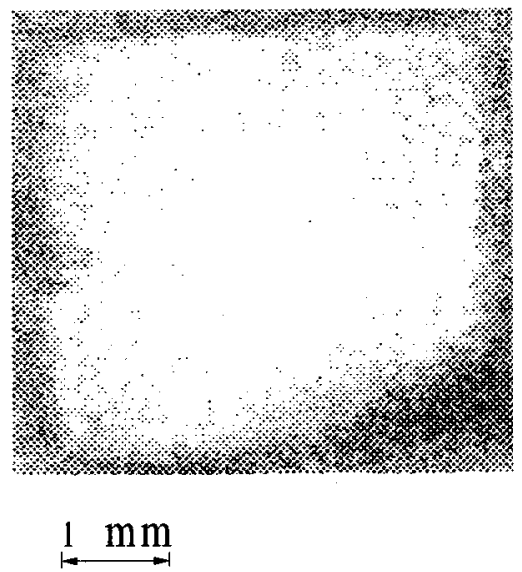

(b)

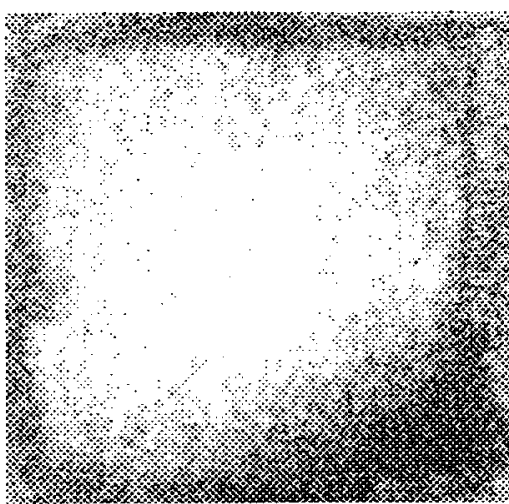

$\stackrel{\mathrm{mm}}{\longrightarrow}$

Fig. 8. Scanning acoustic microscopy image of a specimen of joint produced with In-Au system after: (a) ten cycles and (b) 20 cycles of -50 to $120^{\circ} \mathrm{C}$ thermal cycling.

between the void and the surrounding medium. Fig. 6 presents the acoustic image of a specimen. It is seen from the picture that the joint is nearly void-free.

To confirm the bonding principle and reveal microstructures of the joints fabricated, several specimens were cut into cross- 
sections and polished. A scanning electron microscope (SEM) with energy dispersive X-ray (EDX) spectroscopic system and an optical microscope were used to examine the microstructures and analyze the element compositions. Thickness of the joints was found to be very uniform along the cross-sections. Fig. 7 displays the SEM image of a specimen produced with the In-Au design shown in Fig. 4. The process temperature is $180^{\circ} \mathrm{C}$ with dwell time of $5 \mathrm{~min}$. As we can see from the picture, the bonding layer thickness is $5.0 \mu \mathrm{m}$. Two phases, $\mathrm{AuIn}_{2}$ and indium, exist in the joint. However, EDX analysis also detects some copper within the joint. This could be due to smearing of the copper substrate during the polishing step, or diffusion of copper atoms from the substrate into the joint. No definitive conclusion can be made at this time. Three samples underwent melting temperature test. All have a melting temperature of $157 \pm 5^{\circ} \mathrm{C}$, consistent with the melting point of the pure indium phase.

Despite the large mismatch on coefficient of thermal expansion (CTE) between silicon and copper, no die cracking is observed on all samples produced. To study whether the samples can endure even lower temperature, two samples were subjected to a thermal cycling test between -50 to $120^{\circ} \mathrm{C}$ with a cycle time of $4 \mathrm{~h}$, for a total of 20 cycles. Fig. 8 shows SAM image of the same specimen (shown in Fig. 6) after 20 cycles of test. It is seen that the joint quality has only degraded around the edges of the bonded areas which incurs the highest stress. To find out the strength of the joints, we have performed shear test on one fairly bonded sample (about $80 \%$ bonded) and a well bonded sample. The joint of the sample that was only fairly bonded, came apart at a shear force of about $2.0 \mathrm{~kg}$. For the well bonded sample, the joint did not come apart at a shear force of $3.0 \mathrm{~kg}$, but the silicon die of the specimen was fractured by the shear test tool. Observation of the broken joints under optical microscope shows that the joint materials left on the die surface were more than $50 \%$. According to MIL-STD-883C, the two sheared samples are considered to have met the specification requirement.

\section{CONCLUSION}

In summary, we have applied the oxidation-free fluxless technology to developing an In-Au bonding process on copper substrates. SEM and EDX evaluations on the joint cross sections confirm the basic bonding mechanism and reveal the microstructures of the joints. SEM identified one intermetallic phase $\mathrm{AuIn}_{2}$, The success of this technique clearly indicates that $\mathrm{AuIn}_{2}$ is indeed a stable compound and a good barrier for oxygen penetration. Key features of the technique are: fluxless, oxidation-free, direct deposition of In-Au multilayer composite in high vacuum, good thickness control, good composition control, and nearly void-free.

\section{REFERENCES}

[1] P. T. Vianco and F. G. Yost, "A ban on use of lead-bearing solders: Implications for electronic industry," Sandia National Labs., Albuquerque, NM, Sandia Rep. SAND 92-0211, Apr. 1992.

[2] C. C. Lee, C. Y. Wang, and G. Matijasevic, "A new bonding technology using gold and tin multilayer composite structures," IEEE Trans. Comp., Hybrids, Manufact. Technol., vol. 14, pp. 407-412, June 1991.

[3] C. Y. Wang, Y.-C. Chen, and C. C. Lee, "Directly deposited fluxless lead-indium-gold composite solder," IEEE Trans. Comp., Hybrids Manufact. Technol., vol. 16, pp. 789-793, Dec. 1993.

[4] Y.-C. Chen and C. C. Lee, "Multilayer tin-silver composite solders deposited in high vacuum," in Proc. Int. Electron. Packag. Conf., San Diego, CA, Sept. 24-27, 1995, pp. 258-264.

[5] - "Indium-copper multilayer composites for fluxless oxidation-free bonding," Thin Solid Films, vol. 283, pp. 243-246, 1996.

[6] Y.-C. Chen, W. W. So, and C. C. Lee, "A fluxless bonding technology using indium-silver multilayer composites," IEEE Trans. Comp., Packag., Manufact. Technol. A, vol. 20, pp. 46-51, Mar. 1997.

[7] W. W. So and C. C. Lee, "High temperature joints manufactured at low temperature," in Proc. IEEE Electron. Comp. Technol. Conf., Seattle, WA, May 25-28, 1998, pp. 284-291.

[8] D. F. Bernier, The Nature of White Residue on Printed Circuit Assemblies. Des Plaines, IL: Kester Solder, Oct. 1998.

[9] T. S. Perry, “Cleaning up," IEEE Spectrum, pp. 20-26, Feb. 1993.

[10] H. Okamoto and T. B. Massalski, Eds., Binary Alloy Phase Diagrams. Metal Park, OH: ASM International, 1990, pp. 381-383.

[11] G. W. Powell and J. D. Braun, "Diffusion in the gold-indium system," Trans. Metall. Soc. AIME, vol. 230, pp. 694-699, 1964.

[12] J. Bjøntegaard, L. Buene, T. Finstad, O. Lønsjø, and T. Olsen, "Low temperature interdiffusion in Au/In thin film couples," Thin Solid Films, vol. 101, pp. 253-262, 1983.

[13] V. Simic and Z. Marinkovic, "Thin film interdiffusion of Au and In at room temperature," Thin Solid Films, vol. 41, pp. 57-61, 1977.

[14] C. C. Lee, C. S. Tsai, and X. Cheng, "Complete characterization of thin and thick-flim materials using wideband reflection acoustic microscopy," IEEE Trans. Sonics Ultrason., vol. SU-32, pp. 248-258, Mar. 1985.

[15] G. Matijasevic and C. C. Lee, "Void-free Au-Sn eutectic bonding of GaAs dice and its characterization using scanning acoustic microscopy," J. Electron. Mater., vol. 18, pp. 327-337, 1989.

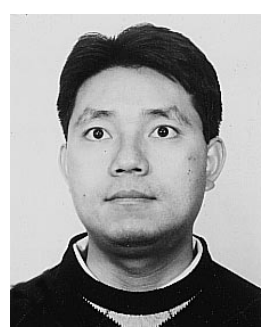

William W. So was born in Hong Kong in 1960. $\mathrm{He}$ received the B.S. degree in electrical engineering from Loyola Marymount University, Los Angeles, CA, in 1983, the M.S. degree in electrical engineering from the University of Michigan, Ann Arbor, in 1984, and the Ph.D. degree in engineering from the University of California, Irvine, in 1999.

He is with Alpha Photonics, Monterey Park, CA. His research interests include fluxless bonding technology for electronic and photonic devices, electronic packaging, vacuum technology, thin film deposition, failure analysis, and microwave devices. He has coauthored 14 research papers. Dr. So is a Member of the Eta Kappa Nu and Tau Beta Pi. 


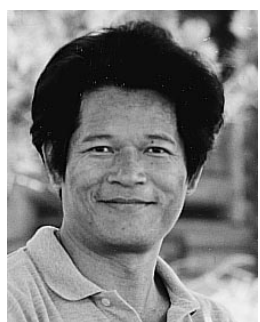

Chin C. Lee (SM'79) was born in Taiwan, R.O.C. He received the B.E. and M.S. degrees in electronics from National Chiao Tung University, Hsinchu, Taiwan, in 1970 and 1973, respectively, and the $\mathrm{Ph} . \mathrm{D}$. degree in electrical engineering from Carnegie Mellon University (CMU), Pittsburgh, PA, in 1979.

From 1979 to 1980, he was a Research Associate with CMU. From 1980 to 1983 , he was with the Electrical Engineering Department, University of California, Irvine, as a Research Specialist. In 1984, he joined the same department as an Assistant Professor and became Professor of electrical and computer engineering in July 1994. He served as the Graduate Advisor of electrical and computer engineering from 1990 to 1994 and is currently serving as the Graduate Advisor for 1999-2000 academic year. His research interests include semiconductor devices, microwave devices, electronic packaging, thermal design of electronic devices, bonding technology, electromagnetic theory, scanning acoustic microscopy, integrated optics, and optoelectronics. His group has invented many fluxless bonding techniques, developed several software packages for thermal analysis of electronic devices, invented and realized a new guided-wave lens structure on GaAs substrate, formulated a new method for the electrostatic analysis of multilayer structures with embedded electrodes, produced several integrated optical devices such as ion exchanged optical waveguides and thermooptic switches, worked on microwave devices based on single crystal ferromagnetic iron films grown on GaAs substrates, and characterized microwave devices up to $50 \mathrm{GHz}$. He has co-authored three book chapters and more than 130 papers in the subject areas mentioned above.

Dr. Lee received the Best Paper Award bestowed by the IEEE Reliability and Electron Devices Group in 1979 for co-authoring the paper "Diagnosis of hybrid microelectronics using transmission acoustic microscopy," and the 1985 to 1986 Outstanding Assistant Professor Award from the School of Engineering, University of California, Irvine for "Outstanding and Balanced Contributions in Research, Teaching and University Service." He is a member of Tau Beta Pi and since 1998 has served on the Program Committee of the IEEE Electronic Components and Technology Conference. He is an Associate Editor of the IEEE TRANSACTIONS ON COMPONENTS AND PACKAGING TECHNOLOGIES. 